\title{
A SIMPLIFICATION IN THE ESTIMATION OF "PROTHROMBIN TIME" FOR THE CONTROL OF ANTICOAGULANT THERAPY
}

\author{
BY \\ J. W. KEYSER AND R. B. PAYNE \\ From the Department of Pathology and Bacteriology, the Welsh National School of Medicine, Cardiff
}

(RECEIVED FOR PUBLICATION OCTOBER 29, 1959)

A modification is described which reduces considerably the amount of pipetting involved in the estimation of " prothrombin time."

The procedure used by the authors is described in full. Particular attention is paid to the preparation and storage of the thromboplastin and to the sterilization of the citrate tubes used for the collection of specimens.

During the last few years the number of patients on treatment with anticoagulant drugs has shown a steady increase, which is likely to be maintained. The simple, one-stage prothrombin estimation of Quick using dried brain is usually considered to be adequate for the control of anticoagulant therapy (cf. Medical Research Council Working Party, 1959) and it has been in use in this laboratory for a number of years. The technique employed here has been essentially that described by Biggs (1951), except for the use of $0.02 \mathrm{M}$ instead of $0.025 \mathrm{M}$ calcium chloride and, more recently, phenol-saline solution in the preparation of the thromboplastin extract (Powell, 1957). It seemed that a considerable saving of time might be effected by the elimination of some of the tedious pipetting involved in the standard procedure. This could be done by mixing in bulk the thromboplastin extract and calcium chloride solution and blowing the plasma into $0.2 \mathrm{ml}$. of this mixture (instead of mixing plasma and thromboplastin and blowing in the calcium chloride). In view of the prevalent assumption that preliminary mixing of plasma and thromboplastin is necessary, a series of plasma samples was tested by both methods.

Soon afterwards it came to our notice that a similar modification had been proposed by Montigel and Pulver (1952). They prepared their mixed reagent by suspending a tablet of thrombokinase "Geigy" in calcium chloride solution, and a thrombokinase-calcium reagent is now commercially available in tablet form (Geigy). However, many workers may wish to be independent of commercial sources of supply, since the necessary reagents are easily prepared.
This paper first presents the experimental results supporting the proposed modification, and then describes in full the procedure employed in this laboratory (Appendix).

\section{Material and Methods}

Blood was collected in citrated tubes (see Appendix) from patients under treatment with anticoagulants (in most cases "dindevan"* but in some " sinthrome"*) and from normal people. The plasma was separated by centrifuging and placed in another tube, from which portions were taken for testing. First, the test was done in the usual way, $0.1 \mathrm{ml}$. of plasma being mixed with $0.1 \mathrm{ml}$. of diluted thromboplastin extract (see Appendix), the mixture left in the water-bath at $37^{\circ} \mathrm{C}$. for 30 seconds and then $0.1 \mathrm{ml}$. of $0.02 \mathrm{M}$ calcium chloride (previously warmed to $37^{\circ} \mathrm{C}$.) blown in. For the proposed modification, $0.2 \mathrm{ml}$. of a mixture of equal volumes of $0.02 \mathrm{M}$ calcium chloride and diluted thromboplastin extract was placed in the tube, which was left in the water-bath for 20 to 30 seconds. The plasma, previously kept at room temperature, was then blown in and the clotting time was noted in the usual way (see Appendix). Over the range $15^{\circ}$ to $30^{\circ} \mathrm{C}$. the temperature of the plasma did not significantly influence the results obtained. Care was taken to perform both tests on a given specimen within a few minutes of each other, so as to obviate errors that might arise from changes in the plasma on standing. Results were related to a normal value obtained by precisely the same technique, as described in the Appendix, and expressed as a "prothrombin clotting time ratio."

\section{Results}

The results of the comparison are summarized in the Table, from which it will be seen that there is a close correlation between the two procedures. \footnotetext{
*Dindevan is phenylindanedione. Sinthrome is 3-[2-acetyl-1-(4-
nitrophenyl)ethyl]-4-hydroxycoumarin.
} 
TABLE

COMPARISON OF PROTHROMBIN CLOTTING TIME RATIOS BY STANDARD PROCEDURE AND PROPOSED MODIFICATION

\begin{tabular}{|c|c|c|}
\hline $\begin{array}{l}\text { Standard } \\
\text { Procedure }\end{array}$ & $\begin{array}{c}\text { Proposed Modification } \\
\text { (Mean and Observed Range) }\end{array}$ & $\begin{array}{c}\text { No. of Plasma } \\
\text { Samples Compared }\end{array}$ \\
\hline $\begin{array}{l}1.0 \\
1.1 \\
1.2 \\
1.3 \\
1.4 \\
1.5 \\
1.6 \\
1.7 \\
1.8 \\
1.9 \\
2.0 \\
2.1 \\
2.2 \\
2.3 \\
2.4 \\
2.5 \\
2.6 \\
2.7 \\
2.8 \\
2.9 \\
3.0 \\
3.1 \\
3.2 \\
3.3 \\
3.4 \\
3.5 \\
3.8 \\
3.9 \\
4.0 \\
4.4 \\
4.6 \\
4.8 \\
5.0 \\
5.2 \\
5.7\end{array}$ & 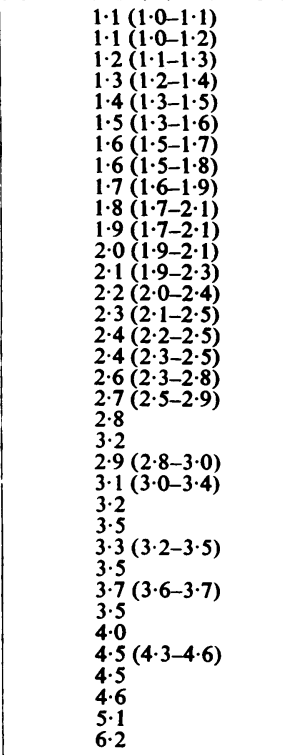 & $\begin{array}{r}3 \\
11 \\
12 \\
13 \\
12 \\
22 \\
16 \\
25 \\
11 \\
19 \\
18 \\
19 \\
11 \\
17 \\
12 \\
2 \\
4 \\
5 \\
4 \\
1 \\
1 \\
2 \\
5 \\
1 \\
1 \\
2 \\
1 \\
2 \\
1 \\
1 \\
2 \\
1 \\
1 \\
1 \\
1\end{array}$ \\
\hline
\end{tabular}

There is a tendency for the simplified procedure to give slightly lower ratios with the more prolonged times.

Fig. 1 illustrates the stability of the thromboplastin-calcium reagent.

\section{Discussion}

These experiments clearly show that the proposed modification is reliable and does not give misleading results. In only one instance was there a serious discrepancy, but it is thought that an error in manipulation had occurred since a specimen of blood obtained from the same patient a few days later gave results in good agreement by both methods.

The tendency of the modified procedure to give slightly lower ratios with the more prolonged times is no disadvantage as long as this is appreciated. It is, indeed, recognized that different procedures give different ratios (Powell, 1957) and it is essential to know which procedure a laboratory employs before deciding on the level to aim at in therapy. According to Biggs (1951), the therapeutic range of prothrombin clottingtime ratios in the control of anticoagulant therapy is 1.5 to 2.5 , i.e., for the technique she describes. Others recommend a range of 2.0 to 2.5 (cf. M.R.C. Working Party, 1959). This latter range would correspond to about 1.9 to 2.4 by the simplified procedure described in this paper. The difference is, in any case, slight and probably is not more than one might expect to find between the results of one laboratory and another, or sometimes even between two people working in the same laboratory.

This procedure, unlike that of Montigel and Pulver, does not involve warming the plasma to $37^{\circ} \mathrm{C}$. before mixing it with the thromboplastincalcium reagent. Furthermore, addition of the plasma to the thromboplastin-calcium reagent, rather than vice versa, appears slightly more convenient in that it permits distribution of the reagent among a number of tubes with a single pipette graduated at $0.2-\mathrm{ml}$. intervals.

\section{A P P E N D I X \\ Method}

Preparation and Storage of Brain.-A human brain is stripped of the membrane and superficial blood vessels, washed with water and then macerated with

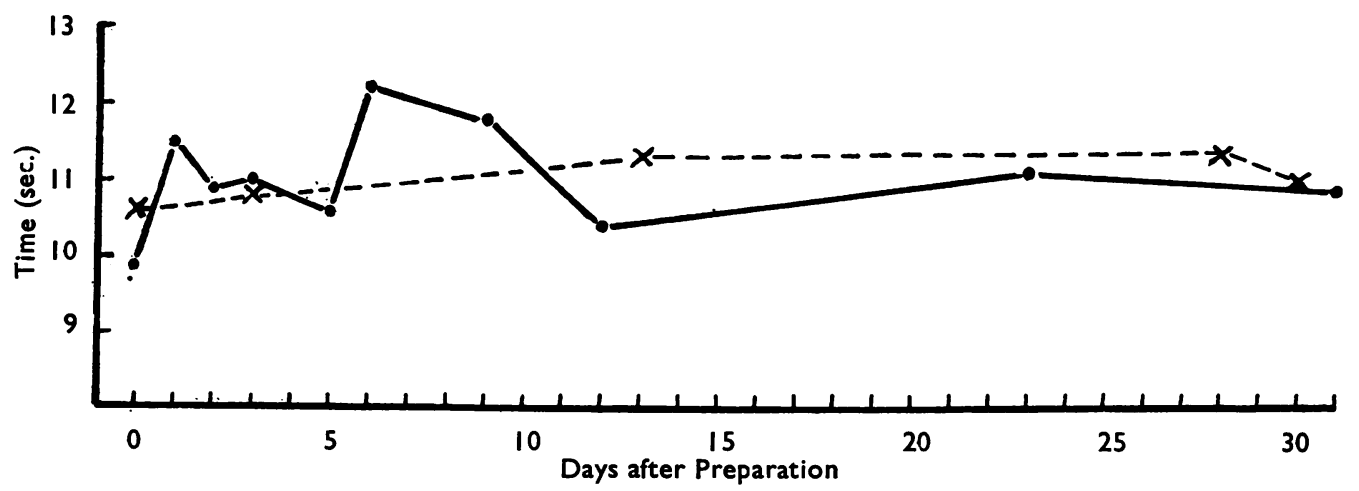

Fig. 1.-Stability of thromboplastin-calcium reagent when stored in the refrigerator: normal values obtained with two preparations over a period of a month. 
acetone in a mortar. (The cerebellum is best excluded on account of the difficulty of removing completely the membranes and blood vessels.) The supernatant fluid is decanted and replaced with fresh acetone and the maceration continued, this procedure being repeated until a friable mass is obtained. The tissue is sufficiently dehydrated when a small portion, removed from the mortar and allowed to dry, can be crumbled to a dry powder. The acetone is then decanted and the brain is spread on large sheets of filter paper to absorb the excess of solvent and allowed to dry. Finally the dried brain, after thorough mixing, is placed in jars and stored in vacuum desiccators containing phosphorus pentoxide and kept in the refrigerator. (The main stock of brain is stored in one desiccator and a smaller amount in another from which it is weighed out as required. In this way the main stock of material is not exposed unnecessarily to air, moisture, and changes in temperature.)

Preparation of Thromboplastin Emulsion.-Dried brain, $2 \mathrm{~g}$., is extracted at $37^{\circ} \mathrm{C}$. for 15 minutes with $20 \mathrm{ml}$. of $0.85 \% \mathrm{w} / \mathrm{v}$ aqueous sodium chloride containing $0.5 \% \mathrm{w} / \mathrm{v}$ phenol, and stirred at fiveminute intervals. After a few hours' standing to allow visible particles to settle, the supernatant fluid is removed ("stock thromboplastin extract"). This should be stored in the refrigerator but not frozen solid. The optimum concentration of thromboplastin for routine use is determined as follows. Normal blood is collected in a citrated tube (see below). The plasma is separated and diluted with four volumes of $0.85 \% \mathrm{w} / \mathrm{v}$ sodium chloride. Then $0.1 \mathrm{ml}$. of the diluted plasma is mixed with $0.1 \mathrm{ml}$. of stock thromboplastin extract, the mixture is incubated at $37^{\circ} \mathrm{C}$. for 30 seconds, $0.1 \mathrm{ml}$. of $0.02 \mathrm{M}$ calcium chloride is blown in, and the time taken for clotting is noted. The test is repeated with dilutions of stock thromboplastin extract in phenol-saline (e.g., $1+1,1+2$, and so on), and the dilution giving the shortest clotting time is selected (" diluted thromboplastin extract"). A portion or all of this diluted thromboplastin extract is then mixed with an equal volume of $0.02 \mathrm{M}$ calcium chloride solution for routine use ("thromboplastincalcium reagent"). This mixture, stored at $4^{\circ} \mathrm{C}$. to $8^{\circ} \mathrm{C}$., retains its potency for several weeks (Fig. 1).

Preparation of Citrated Tubes.-Amounts, each of $0.2 \mathrm{ml}$., of a $3.8 \% \mathrm{w} / \mathrm{v}$ aqueous solution of sodium citrate dihydrate (stored in the refrigerator) are measured into tubes $(75 \times 10 \mathrm{~mm}$.) marked at exactly $2 \mathrm{ml}$. The tubes are then securely stoppered with rubber bungs and are autoclaved at $15 \mathrm{lb}$. for 20 minutes. It is convenient to autoclave the tubes in stainless steel racks stacked on top of one another and held together by rods, the top layer of tubes being covered by a metal plate: in this way the bungs are kept in place and no air enters when the tubes are allowed to cool. After autoclaving, each tube is labelled with a "sterile" label bearing the date of preparation and covering the bung. Tubes are issued to the wards and out-patient department with instructions that they be stored in an upright position.
Collection of Blood.-Blood is collected in the usual way and the tube is filled exactly to the $2 \mathrm{ml}$. mark. The plasma is separated by centrifugation.

The Test.-Thromboplastin-calcium reagent, $0.2 \mathrm{ml}$., is placed in a small test-tube (about $60 \times 10 \mathrm{~mm}$.), which is then left in the water-bath at $37^{\circ} \mathrm{C}$. for 20 to 30 seconds. Citrated plasma at room temperature, $0.1 \mathrm{ml}$., is blown in, a stop-watch being started at the same time. The tube is slanted, and rotated gently about its long axis until the first appearance of fibrin strands. These are seen clearly if the tube is held underneath a light and against a dark background. The test is performed in duplicate at least. (When the test is repeated the tube is kept in the water-bath to within about five seconds of the time indicated by the first estimation.) Normal plasma specimens are tested in the same way and the result obtained with the patient's plasma is expressed as a ratio, viz. :

Prothrombin clotting time ratio $=$

Clotting time observed with patient's plasma

Average clotting time observed with normal plasma

\section{Notes on the Method}

Preparation and Storage of Dried Brain.-These are essentially as described by Aggeler, Howard, Lucia, Clark, and Astaff (1946), with slight modifications. In our experience the dried brain, stored as described, retains its potency for at least a year.

Standardization of Thromboplastin.-The method is that of Biggs (1951), except for the use of phenolsaline.

Thromboplastin Extract.-The use of phenol to preserve emulsions of fresh brain was suggested by Toohey (1950); and Powell (1957), working in this laboratory, showed that extracts of dried brain can be preserved in the same way for at least two weeks. Powell's findings can be confirmed here. It should be noted that freezing the extract solid in the deep-freeze results in rapid loss of activity.

Tubes for Blood Specimens.-Citrate is used as the anticoagulant rather than oxalate because of the possibility of loss of prothrombin by adsorption on the precipitate of calcium oxalate. However, the possibility of deterioration of citrate solutions as a result of the growth of moulds or bacteria has apparently received little attention. The use of contaminated tubes may result in grossly misleading values. Autoclaving the stoppered tubes containing citrate is more likely to ensure sterility than simply pipetting a sterile citrate solution into the tubes under aseptic conditions.

\section{REFERENCES}

Aggeler, P. M., Howard, J., Lucia, S. P., Clark, W., and Astaff, A. (1946). Blood, 1, 220.

Biggs, R. (1951). Prothrombin Deficiency. Blackwell Scientific Publications, Oxford.

Medical Research Council Working Party (1959). Brit. med. J., 1, 803.

Montigel, C., and Pulver, R. (1952). Schweiz. med. Wschr., 82, 132. Powell, D. E. B. (1957). J. clin. Path., 10, 262.

Toohey, M. (1950). Brit. med. J., 1, 518. 